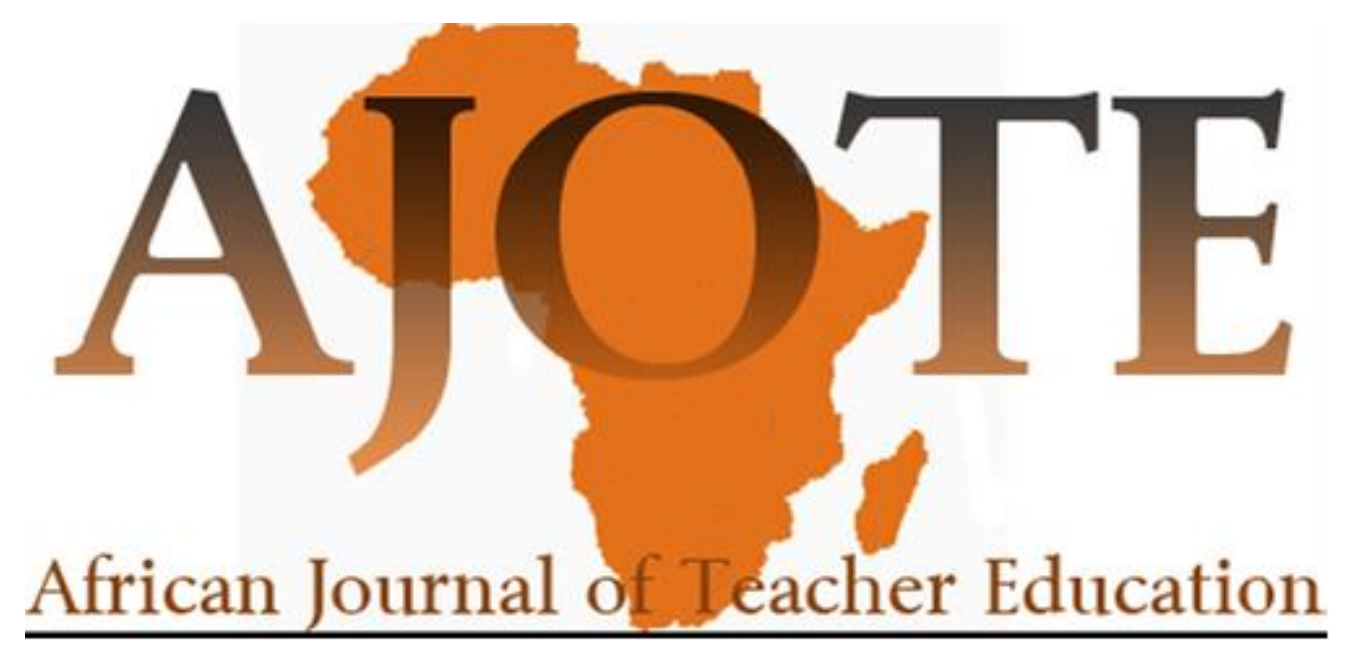

\title{
ETHical Conflicts and Moral Dilemmas EXPERIEnCED by PHysical EduCation TEACHERS IN TANZANIA
}

\author{
Stephen Mabagala \\ University of Dar Es Salaam, Tanzania
}

\begin{abstract}
The purpose of this study was to explore the ethical conflicts and moral dilemmas (ECMD) experienced by Physical Education (PE) teachers. The study also sought to explore the influence of demographic and institutional characteristics on the ECMD experienced by PE teachers. The experience of PE teachers is unique because of the nature of their duties in and outside the classroom and school environments where there are a lot of interactions. The study utilized descriptive survey design and was conducted in secondary schools and teachers' colleges that had PE and sport programs. Purposive sampling was adopted to select PE teachers, students and heads of institutions and data were collected through questionnaire. Results revealed that $P E$ teachers faced ethical conflicts and moral dilemmas in their duties $(M=3.4, S D=.79)$. ECD facing PE teachers differed significantly across institutional location [t $(411.33)=2.453, p$ $=.015)]$, institutional ownership $[F(3,788)=5.01, p=.002)]$ and type of institution $[(t(50)=-$ $2.45, p=.019)]$. There were no significant differences across age categories $[F(4,47)=.500, p$ $=.736)]$, educational levels $[F(3,48)=1.648, p=.191)]$, gender $[t(50)=.383, p=.703]$, marital status $[t(50)=.439, p=.663]$ and teaching experience $[F(3,48=.638, p=.594]$. It was concluded that ECD are prevalent in secondary schools and teachers colleges. PE teachers whose institutions are located in urban areas face more ECD than those located in rural areas. Religious and military-owned institutions face less ECD than government and privately-owned institutions. Moreover, PE teachers in secondary schools face more ECD than those in teachers' colleges. It was recommended that there is a need to strengthen professional development courses for teachers and emphasize the teaching of moral and professional ethics in the teacher education programs; and improve the teaching and learning environment.

Keywords: ethical conflict, moral dilemma, Tanzania Physical Education, Physical Education teachers.
\end{abstract}




\section{Introduction}

One of the demands of any profession is to maintain acceptable professional standards (Hinds, 2005). In the teaching profession, teachers' professional behaviors inside and outside the classroom have far reaching impacts on their behavior and their overall performance and thus the learning outcomes (Bennell \& Akyeampong, 2007). Consequently, teachers need to be aware of their moral and ethical responsibilities in their relationships with students (Melo, 2003). This relationship is of an unequal and dependent nature. The nature of teaching also lends itself to being of an ethical and moral nature because of the complexity of the teachers' tasks. The complexity stems from the variety of tasks that a teacher performs. For example, teachers need to be able to act on the spot, respond effectively and fairly to students, deliver engaging lessons in a limited amount of time, and assess various levels of students' work and abilities (Melo, 2003).

As for Physical Education (PE) teachers, their experience is unique because of the nature of their duties in and outside the classroom and school contexts. For example, during instruction, there is physical handling of the learners and shouting especially when demonstrating and assessing a skill. Moreover, other than being classroom teachers, PE teachers, most often double as the sports coaches. This aspect compels them to travel outside school with their students. This creates the teacher (coach/trainer) - learner relationship which most often is a multidimensional and continual relationship that flourishes within and outside the school. Through participation in $\mathrm{PE}$ and school sport, both students and teachers get very close to each other and break some social barriers. This makes both PE teachers and students to be free with one another and may develop some bonds. Moreover, sports demand minimal clothing which can lead to unintended intimate desires. Thus, all these lead to ethical issues that need to be addressed (Pehlivan, 1998).

\section{Purpose of the Study}

a. Determine the prevalence of ethical conflicts and moral dilemmas experienced by physical education teachers in their implementation of the professional code of ethics and conduct in Tanzania.

b. Find out whether demographic and institutional variables influence the ethical conflicts and moral dilemma that PE teachers face.

\section{Research Hypotheses}

$\mathrm{Ho}_{1}$ : The ethical conflicts and moral dilemmas faced by PE teachers would not significantly differ across their demographic variables.

$\mathrm{Ho}_{2}$ : The ethical conflicts and moral dilemmas faced by PE teachers would not significantly differ in relation to their institutional variables.

\section{Methods and Procedure}

The study employed a descriptive survey research design to gather data. In this study, the dependent variables were ethical conflicts and dilemmas. The independent variables were the demographic factors (age, gender, marital status, years of teaching experience and educational level) of PE teachers. Other independent variables were institutional (ownership, type and location) characteristics. The study was carried out in Tanzania in secondary schools and teachers' colleges that had physical education and sport programs.

\section{Participants}


A sample of 792 respondents participated in this study, and it comprised 52 PE teachers, 720 students and 20 heads of institutions. Respondents were selected based on presence of PE programs and involvement in PE lessons as the case for teachers and students. The heads of institutions were selected because of their administrative role and functions of overseeing teachers' conduct and discipline.

\section{Instruments}

The instruments used for data collection were closed-ended questionnaires. Participants responded on a 5-point Likert Scale ranging from strongly agree (5), agree (4), no opinion (3), disagree (2) to strongly disagree (1). After respondents had filled in the questionnaires, responses were rearranged as most prevalence (5), high prevalence (4), prevalence (3), low prevalence (2), and least prevalence (1). The highest score on each item indicated the prevalence of conflicts and dilemma while the least score indicated absence or little conflicts and dilemmas.

\section{Data Analysis}

Data collected from the questionnaires were coded and analyzed using the Statistical Package for Social Sciences (SPSS) program, version 19. Data were calculated in percentages, means and standard deviations for easy interpretation of the information. Independent t-test and one-way analysis of variance (ANOVA) were also calculated to test significant mean differences between variables at 0.05 level of significance and the Tukey post hoc test was employed to further explain significant mean differences.

\section{Results}

Ethical conflicts and moral dilemmas (ECMD) facing PE teachers in Tanzania The results of participants' responses with regard to the types of ethical conflicts and dilemmas facing PE teachers in secondary schools and teachers' colleges in Tanzania are presented in Table 1.

Table 1 Descriptive Data on Ethical Conflicts and Moral Dilemmas Facing PE Teachers

\begin{tabular}{|c|c|c|c|c|c|c|c|c|}
\hline \multirow[t]{2}{*}{$\begin{array}{l}\text { Ethical conflicts and moral } \\
\text { dilemma }\end{array}$} & \multicolumn{2}{|c|}{ Students } & \multicolumn{2}{|c|}{$\begin{array}{l}\text { PE } \\
\text { Teachers }\end{array}$} & \multicolumn{2}{|c|}{ Heads } & \multicolumn{2}{|c|}{ Total } \\
\hline & $\mathbf{M}$ & SD & $\mathbf{M}$ & SD & $\mathbf{M}$ & SD & $\mathbf{M}$ & SD \\
\hline $\begin{array}{l}\text { Lack of teaching and learning } \\
\text { resources }\end{array}$ & 4.20 & .56 & 4.35 & .43 & 4.19 & .33 & 4.25 & .44 \\
\hline Policy changes and lack of support & 3.95 & .43 & 3.99 & .57 & 3.76 & 1.23 & 3.90 & .74 \\
\hline Lack of training in the codes & 3.96 & .42 & 3.48 & 1.36 & 3.70 & 1.34 & 3.36 & 1.39 \\
\hline $\begin{array}{l}\text { Lack of cooperation from parents } \\
\text { and community. }\end{array}$ & 3.37 & 1.41 & 3.37 & 1.22 & 2.75 & 1.29 & 3.36 & 1.39 \\
\hline $\begin{array}{l}\text { Compromise of teaching } \\
\text { responsibilities with private duties. }\end{array}$ & 3.33 & 1.32 & 2.75 & 1.41 & 3.55 & .89 & 3.29 & 1.32 \\
\hline Pressure to win and fear of defeat & 3.18 & 1.37 & 3.17 & 1.31 & 3.45 & 1.00 & 3.19 & 1.36 \\
\hline $\begin{array}{l}\text { Desire for recognition and } \\
\text { promotion }\end{array}$ & 3.11 & 1.25 & 3.27 & 1.30 & 3.40 & .88 & 3.12 & 1.25 \\
\hline Mismanagement of school resources & 2.84 & 1.40 & 3.08 & 1.34 & 2.80 & 1.32 & 2.85 & 1.39 \\
\hline
\end{tabular}




\begin{tabular}{|c|c|c|c|c|c|c|c|c|}
\hline $\begin{array}{l}\text { Abuses in supply/purchase of } \\
\text { materials and equipment for PE and } \\
\text { sports }\end{array}$ & 2.86 & 1.38 & 2.56 & 1.36 & 2.75 & 1.29 & 2.83 & 1.38 \\
\hline Poor relationships with students. & 2.83 & 1.35 & 2.56 & 1.11 & 2.85 & 1.31 & 2.82 & 1.33 \\
\hline $\begin{array}{l}\text { Abuses in assessment and } \\
\text { evaluation }\end{array}$ & 2.76 & 1.38 & 2.58 & 1.38 & 2.45 & .83 & 2.74 & 1.36 \\
\hline Substance abuse among students & 2.92 & 1.37 & 2.52 & 1.24 & 3.00 & 1.26 & 2.71 & 1.36 \\
\hline Verbal and physical abuse. & 2.74 & 1.40 & 2.37 & 1.24 & 2.55 & 1.28 & 2.71 & 1.39 \\
\hline Sexual harassment and abuse. & 2.71 & 1.38 & 2.37 & 1.22 & 2.80 & 1.20 & 2.69 & 1.37 \\
\hline Total & 3.05 & .91 & $\begin{array}{l}3 . \\
02\end{array}$ & .97 & 3.04 & .77 & 3.04 & .79 \\
\hline
\end{tabular}

Table 1 indicates that overall, PE teachers in secondary schools and teachers' colleges in Tanzania experience ethical conflicts and dilemmas $(\mathrm{M}=3.04, \mathrm{SD}=.79)$. Findings further indicate that lack of teaching and learning resources was ranked highest $(\mathrm{M}=4.25, \mathrm{SD}=44)$, policy changes and lack of support was ranked second $(\mathrm{M}=3.90, \mathrm{SD}=.74)$, lack of training in the codes $(\mathrm{M}=3.36, \mathrm{SD}=1.39)$ and lack of cooperation from parents and community $(\mathrm{M}=3.6$, $\mathrm{SD}=1.39$ ) were ranked third and fourth respectively, compromise of teaching responsibilities with private duties was ranked fifth $(\mathrm{M}=3.29$, $\mathrm{SD}=1.32)$, pressure to win and fear of defeat was ranked sixth $(\mathrm{M}=3.19, \mathrm{SD}=1.36)$, and desire for recognition and promotion was ranked seventh $(\mathrm{M}=3.12, \mathrm{SD}=1.25)$.

\section{Ethical conflicts and moral dilemmas facing PE teachers across demographic variables}

The research objective was to find out whether demographic variables influence the Ethical Conflicts and Moral Dilemma (ECMD) that PE teachers face. The hypothesis stated that the ethical conflicts and moral dilemmas faced by PE teachers would not significantly differ across their demographic characteristics. The hypothesis was further split into sub-hypotheses that captured age, educational level, gender, marital status and teaching experience of PE teachers.

Age categories. Results on the responses of ethical conflicts and dilemmas facing PE teachers across their age categories are presented in Table 2.

Table 2 Descriptive Data for Ethical Conflicts and Moral Dilemmas Facing PE Teachers across Age Categories

\begin{tabular}{llll}
\hline Age Groups & $\mathbf{n}$ & Mean & SD \\
\hline 25-30 years & 19 & 3.01 & 1.08 \\
31-35 years & 8 & 2.96 & .57 \\
36-40 years & 6 & 3.20 & .55 \\
41-45 years & 10 & 2.97 & 1.19 \\
46+ years & 9 & 2.96 & .1 .07 \\
\hline Total & 52 & 3.02 & .97 \\
\hline
\end{tabular}

Table 2 shows there were irregular pattern of variations within age categories, with only respondents of age 36-40 years reporting prevalence of ethical conflicts and dilemmas $(\mathrm{M}=3.20$, $\mathrm{SD}=.55$ ) and four other categories reporting less prevalence of ECD. In order to determine 
whether the mean differences were significant or not, a one-way ANOVA was used to test for differences among the five age categories. Results are presented in Table 3.

Table 3 One-way ANOVA to Test the Statistical Significance Difference between Means of the ECD Facing PE Teachers across their Age Categories

\begin{tabular}{llllll}
\hline & Sum of Squares & df & Mean Square & F & Sig. \\
Between Groups & 1.980 & 4 & .495 & .500 & .736 \\
Within Groups & 46.495 & 47 & .989 & & \\
Total & 48.475 & 51 & & & \\
\hline$* p<.05$ & & & & &
\end{tabular}

Results in Table 3 show that there were no significant differences in ethical conflicts and dilemmas faced by PE teachers across their age categories $[F(4,47)=.500, p=.736)]$. Therefore, the null hypothesis that the ethical conflicts and dilemmas faced by PE teachers would not significantly differ across their age categories was not rejected. This implies that the ethical conflicts and dilemma faced by PE teachers were not influenced by age.

Educational levels. The second sub-hypothesis stated that the ethical conflicts and dilemmas faced by PE teachers would not significantly differ across their education levels. Results are presented in Table 4.

Table 4 Descriptive Data for Ethical Conflicts and Moral Dilemmas Facing PE Teachers across their Educational Levels

\begin{tabular}{llll}
\hline Education Level & $\mathbf{n}$ & Mean & SD \\
\hline Certificate & 4 & 3.45 & .56 \\
Diploma & 15 & 2.90 & .77 \\
Degree & 31 & 2.62 & 1.02 \\
Postgraduate & 2 & 3.70 & 1.84 \\
\hline Total & 52 & 3.02 & .97 \\
\hline
\end{tabular}

Table 4 shows that postgraduate holders had the highest mean $(\mathrm{M}=3.70, \mathrm{SD}=1.84)$ followed by certificate holders $(\mathrm{M}=3.45, \mathrm{SD}=.56)$. On the other hand, degree holders reported low prevalence $(\mathrm{M}=2.62, \mathrm{SD}=1.02)$ followed by diploma holders $(\mathrm{M}=2.90, \mathrm{SD}=.77)$. To determine whether the mean differences were significant or not, a one- way ANOVA was computed. Results are shown in Table 4.47.

Table 5 One-way ANOVA to Test the Statistical Significance Difference between Means of the ECMD Facing PE Teachers across their Educational Levels

\begin{tabular}{llllll}
\hline & Sum of Squares & df & Mean Square & F & Sig. \\
Between Groups & 4.526 & 3 & 1.509 & 1.648 & .191 \\
Within Groups & 43.948 & 48 & .916 & & \\
\hline
\end{tabular}




\begin{tabular}{lll}
\hline Total & 48.475 & 51 \\
\hline$* p<.05$ & &
\end{tabular}

Results in Table 5 show that there were no significant differences $[\mathrm{F}(3,48)=1.648, \mathrm{p}=.191)]$ in the ethical conflicts and dilemma facing PE teachers across their educational levels. Based on the above results, the null hypothesis that the ethical conflicts and dilemmas faced by PE teachers would not significantly differ in relation to their education levels was not rejected.

Gender. The third sub-hypothesis stated that the ethical conflicts and dilemmas faced by PE teachers would not significantly differ in relation to their gender. Results are presented in Table 6.

\section{Table 6 Descriptive Data and t-Test for Ethical Conflicts and Moral Dilemmas Facing PE Teachers by Gender}

\begin{tabular}{lll|ll} 
Gender & $\mathbf{n}$ & Mean & SD & t-Value \\
Male & 41 & 3.03 & .96 & .703 \\
Female & 11 & 3.01 & 1.06 & \\
\hline Total & 52 & 3.02 & .97 & \\
\hline
\end{tabular}

$* p<.05$

Table 6 shows that both male and female respondents reported prevalence of ethical conflicts and dilemmas $(\mathrm{M}=3.03, \mathrm{SD}=.96 \& \mathrm{M}=3.01, \mathrm{SD}=1.06$ respectively $)$. The mean difference was very minimal indicating that their opinions concerning ECD facing PE teachers was similar. In order to determine whether the mean differences were significant or not, an independent t-test was computed. Results reveal that there was no significant difference $[t(50)=.383, p=.703]$. Therefore, the null hypothesis that there would be no significant difference in ethical conflicts and dilemma facing male and female PE teachers was not rejected. Both male and female respondents reported the same opinions concerning the ethical conflicts and dilemmas facing PE teachers. The findings imply that both female and male PE teachers experienced the same ethical conflict and dilemma in their responsibilities.

Marital status. The fourth sub-hypothesis stated that the ethical conflicts and dilemmas faced by PE teachers would not significantly differ across their marital status. Results are shown in Table 7.

Table 7 Descriptive Data and t-test for Ethical Conflicts and Moral Dilemmas Facing PE Teachers across Marital Status

\begin{tabular}{lccc|c}
$\begin{array}{l}\text { Marital } \\
\text { Status }\end{array}$ & $\mathbf{n}$ & Mean & SD & t- values \\
\hline Single & 15 & 3.04 & .97 & .663 \\
Married & 37 & 3.01 & .99 & \\
\hline Total & 52 & 3.02 & .98 & \\
\hline$*<<.05$ & & & &
\end{tabular}


Results in Table 7 reveal that PE teachers who were single scored relatively higher $(\mathrm{M}=3.04$, $\mathrm{SD}=.97)$ than those who were married $(\mathrm{M}=3.01, \mathrm{SD}=.99)$. This implies that single $\mathrm{PE}$ teachers faced ECD more than married PE teachers. But, this difference was not significant [ $\mathrm{t}$ $(50)=.439, \mathrm{p}=.663]$. Thus, the hypothesis that there would be no significant differences between the ethical conflicts and dilemmas facing PE teachers across their marital status was not rejected.

Teaching experience. The fifth sub-hypothesis stated that the ethical conflicts and moral dilemmas faced by PE teachers would not significantly differ in relation to their teaching experience. Results are presented in Table 8.

\section{Table 8 Descriptive Data for Ethical Conflicts and Moral Dilemmas Facing PE Teachers across their Teaching Experience}

\begin{tabular}{l|lll}
\hline Teaching Experience & $\mathbf{n}$ & Mean & SD \\
\hline 1-5 years & 30 & 3.01 & 1.01 \\
6-10 years & 9 & 2.89 & .88 \\
11-15 years & 4 & 3.15 & .37 \\
Over 15 years & 9 & 3.04 & 1.16 \\
\hline Total & 52 & 3.02 & .98 \\
\hline
\end{tabular}

Table 8 shows that PE teachers with teaching experience of 6-10 years reported lower $(\mathrm{M}=2.89$, $\mathrm{SD}=.88$ ) experience of ethical conflicts and moral dilemma than others. In order to determine whether the mean differences were significant or not, a one- way ANOVA was computed as shown in Table 9.

Table 9 One-way ANOVA to Test the Statistical Significance Difference between Means of the ECMD Facing PE Teachers across their Teaching Experience

\begin{tabular}{llllll}
\hline & Sum of Squares & df & Mean Square & F & Sig. \\
\hline Between Groups & 1.859 & 3 & .620 & .638 & .594 \\
Within Groups & 46.616 & 48 & .971 & & \\
Total & 48.475 & 51 & & & \\
\hline$* p<.05$
\end{tabular}

Results in Table 9 reveal that there were no significant differences $[\mathrm{F}(3,48=.638, \mathrm{p}=.594)]$ in the ethical conflicts and moral dilemma facing PE teachers with varying years of teaching experience. Therefore, the hypothesis that there would be no significant difference between the ethical conflicts and dilemma faced by PE teachers in relation to their teaching experience was not rejected. All PE teachers irrespective of their teaching experience reported that ethical conflicts and dilemma were prevalent.

Institutional variables. The research objective was to find out whether institutional variables influence the ethical conflicts and moral dilemma that PE teachers face. It was hypothesized that the ethical conflicts and dilemmas faced by PE teachers would not significantly differ in relation to their institutional characteristics. The hypothesis was further subdivided into three hypothesis that captured location, ownership and type of the institution. 
Institutional location. The sub-hypothesis stated that there would be no significant difference in the ethical conflicts and moral dilemmas faced by PE teachers in relation to their location. Results are shown in Table 10.

\section{Table 10 Descriptive Data and t-Test for Ethical Conflicts and Dilemmas Facing PE Teachers by their Institutional Location}

\begin{tabular}{ll|lll}
\hline Location & $\mathbf{n}$ & Mean & SD & t-Value \\
\hline Urban & 583 & 3.08 & .94 & .015 \\
Rural & 209 & 2.91 & .83 & \\
\hline Total & 792 & 3.04 & .91 & \\
\hline
\end{tabular}

$* p<.05$

Table 10 indicates that PE teachers in urban areas experienced more ethical conflicts and moral dilemmas than those in rural areas. To determine whether the observed difference was significant or not, an independent t-test was computed. Results show that there was significant difference [t $(411.33)=.2 .453, \mathrm{p}=.015)]$ in ethical conflicts and moral dilemmas faced by PE teachers in urban areas $(\mathrm{M}=3.08, \mathrm{SD}=.94)$ and $\mathrm{PE}$ teachers in rural areas $(\mathrm{M}=2.9, \mathrm{SD}=83)$. Therefore, the null hypothesis that there would be no significant difference in the type of ethical conflicts and moral dilemmas faced by PE teachers in urban and rural areas was rejected. PE teachers in urban areas experienced more ethical conflicts and moral dilemmas than PE teachers in rural areas.

Institutional ownership. The sub-hypothesis stated that there would be no significant difference in the ethical conflicts and dilemmas faced by PE teachers in relation to their institutional ownership. Results are presented in Table 11.

Table 11 Descriptive Data for Ethical Conflicts and Moral Dilemmas Facing PE Teachers by their Institutional Ownership

\begin{tabular}{llll}
\hline Ownership & n & Mean & SD \\
Government & 695 & 3.07 & .94 \\
Private & 17 & 3.17 & .79 \\
Military & 50 & 2.80 & .43 \\
Religious & 30 & 2.51 & .73 \\
\hline Total & 792 & 3.04 & .91 \\
\hline
\end{tabular}

Results in Table 4.53 indicate that PE teachers in private and Government institutions reported prevalence of ECMD whilst PE teachers in religious and military-owned institutions reported less prevalence. Results in Table 11 also show that PE teachers in private institutions relatively faced ECMD more than PE teachers in other institutions, whilst PE teachers in religious-owned institutions faced relatively low prevalence of ECMD. To determine whether there were significant differences between the observed means or not, a one-way ANOVA was computed. Results are presented in Table 12. 
Table 12 One-way ANOVA to Test the Statistical Significance Difference between Means of the ECMD Facing PE Teachers by Institutional Ownership

\begin{tabular}{llllll}
\hline & Sum of Squares & df & Mean Square & F & Sig. \\
\hline Between Groups & 12.285 & 3 & 4.095 & 5.01 & .002 \\
Within Groups & 644.032 & 788 & .817 & & \\
Total & 656.317 & 791 & & & \\
\hline
\end{tabular}

$* p<.05$

The findings in Table 12 show that there were significant differences $[\mathrm{F}(3,788)=5.01$, $p$ $=.002)]$ in the ECMD faced by PE teachers across their institutional ownership. To further examine the differences, a post hoc test was conducted and results are shown in Table 13.

Table 13 Tukey HSD Post Hoc Results for ECMD Facing PE Teachers across Institutional Ownership

\begin{tabular}{|ll|l|l|l|}
\hline Ownership (I) & Ownership (J) & Mean Difference (I-J) & Std. Error & Sig. \\
\hline Government & Private & -.09752 & .22193 & .972 \\
& Military & .26777 & .13237 & .180 \\
& Religious & $.56499^{*}$ & .16858 & .005 \\
\hline Private & Government & .09752 & .22193 & .972 \\
& Military & .36529 & .25382 & .475 \\
& Religious & .66252 & .27444 & .075 \\
\hline Military & Government & -.26777 & .13237 & .180 \\
& Private & -.36529 & .25382 & .475 \\
& Religious & .29722 & .20878 & .485 \\
\hline Religious & Government & $-.56499^{*}$ & .16858 & .005 \\
& Private & -.66252 & .27444 & .075 \\
& Military & -.29722 & .20878 & .485 \\
\hline
\end{tabular}

*. The mean difference is significant at the 0.05 level.

Table 13 reveals that a statistically significant difference was found between government-owned institutions and religious-owned institutions $(.56499, \mathrm{p}=.005)$. However, there was no significant difference between private institutions and Government, military and religious institutions. There was also no significant difference between military-owned institutions and government, private and religious-owned institutions. Furthermore, there was no significant difference between religious-owned institutions and private and military-owned institutions. Based on the above results, the null hypothesis that there would be no significant difference between ethical conflicts and moral dilemma faced by PE teachers across institutional ownership was rejected. Significant differences were noted between government and religious-owned institutions. The reason for this may be due to the quality of services that teachers, and PE teacher in particular, get from the owners of the institutions. 
Type of institution. The sub-hypothesis stated that there would be no significant difference in the ethical conflicts and moral dilemmas faced by PE teachers in relation to their type of institution. The findings are presented in Table 14.

\section{Table 14 Descriptive Data and t-Test for Ethical Conflicts and Moral Dilemmas Facing PE Teachers by their Type of Institutions}

\begin{tabular}{ll|lll}
\hline Type of Institution & $\mathbf{n}$ & Mean & SD & t-Value \\
\hline Secondary & 136 & 3.08 & .95 & .000 \\
T/College & 656 & 2.82 & .66 & \\
\hline Total & 792 & 3.04 & .91 & \\
\hline
\end{tabular}

$* p<.05$

Table 14 indicates that PE teachers in secondary schools experienced more ethical conflicts and moral dilemmas than those in teachers' colleges. In order to determine whether the difference in means was significant or not, an independent t-test was computed. Results show that there was significant difference $[\mathrm{t}(266.847)=-.829, \mathrm{p}=.000)]$ in ethical conflicts and dilemmas faced by $\mathrm{PE}$ teachers in secondary schools $(\mathrm{M}=3.08, \mathrm{SD}=.95)$ and $\mathrm{PE}$ teachers in teachers' colleges $(\mathrm{M}$ $=2.82, \mathrm{SD}=.66$ ). Therefore, the null hypothesis that there would be no significant difference in ethical conflicts and moral dilemma faced by PE teachers in secondary schools and teachers' colleges was rejected. PE teachers in secondary schools faced more ethical conflicts and moral dilemmas than PE teachers in teachers' colleges.

\section{Discussion}

The findings of this study have revealed that ECMD are prevalent among PE teachers in secondary schools and teachers' colleges, and are related to both institutional and personal factors. Ethical conflicts which were of institutional nature were those concerning lack of teaching and learning materials, policy changes, ignorance of the codes and lack of training in the codes, and lack of cooperation from parents and community. Those of personal nature were compromise of teaching responsibilities with private duties and desire for recognition and promotion. Pressure to win and fear of defeat could be a result of both institutional and personal factors. The PE teacher can be put under pressure by the school administration to win trophies and not just be mere participants in competitions. This can force PE teachers to train students with only one focus of winning at all cost to please the administration and gain recognition or promotion. These findings concur with other studies such as those of Anangisye and Barrett (2005) who identified mismanagement of school resources as one of the ethical conflicts befalling teacher professionalism and ethics. The findings are also in line with those of Van Nulland and Khandalwal (2006) who identified mismanagement of school funds and resources, and abuse in supply and purchase of materials as serious ethical conflicts experienced by teachers.

The findings of the study have revealed no significant difference in ECMD facing PE teachers across their demographic variables of age, educational level, gender, marital status and teaching experience. These findings are in line with those of Holloman (1999), and Zhao and Bi (2003) and Luk, et al (2010) who found no statistically significant difference between the variables of ethical dilemma and demographic variables.

The findings have also indicated significant difference in ECMD facing PE teachers by their institutional variables of location, ownership and type of institution. The findings are in line 
with those of Sumra (2004) who observed that teachers in rural areas feel that teaching is a respected profession whereas teachers in urban areas where teachers are the lowest earning professionals; there is less respect for the profession. As for religious-owned institutions, Luk and Shek (2006) found out that high levels of religious involvement are related to psychological well-being. As discussed earlier, private institutions are less controlled than all other institutions. This could be the reason for higher prevalence of ethical conflicts and dilemmas in private institutions.

\section{Conclusions and Recommendations}

Physical Education teachers in Tanzania face ethical conflicts and dilemmas related to institutional and personal nature. Lack of teaching and learning resources are the major ethical conflicts for PE teachers. Additionally, PE teachers do not get training for the teachers' professional code of ethics and conduct. There is therefore, a need for the government to emphasize professional development courses among (PE) teachers and improve the funding of the education system in order to improve the standard of teaching PE in schools and colleges.

\section{REFERENCES}

Anangisye, W.A. L., \& Barrett, A. (2005). "Professional identity and misconduct: Perspectives of Tanzanian teachers," Southern African Review of Education (SARE) with Education with Production (EWP), 11, 5-22.

Ary, D., Jacobs, L. C., \& Razavieh, A. (2002). Introduction to research in education. (6 $6^{\text {th }}$ ed.). Belmont, CA: Wadsworth/Thomson Learning.

Balci, A. (2001). Research in social sciences: Method, technique and principles. Ankara: Pegem Publishing.

Bennell, P., \& Akyeampong, K. (2007). Teacher motivation in Sub-Saharan Africa and South Asia. London: Department of International Development.

Cooper, R. (2006). Ethical problems and their resolution amongst UK community pharmacists: A qualitative study. Unpublished PhD dissertation. Nottingham, UK, University of Nottingham.

Fowler, F. J. (2001). Survey research methods. Thousand Oaks, CA: Sage Publications.

Hinds, H. (2005). OECS generic teachers' code of ethics. Castries, St. Lucia: OECS Education Reform Unit/Education, Training, Technology and Management Consulting (TECSULT).

Holloman, H. L. (1999). Factors related to burnout in First year teachers in South Carolina. unpublished $\mathrm{PhD}$ thesis, University of South Carolina. 
12 Ethical Conflicts and Moral Dilemmas Experienced by Physical Education Teachers in Tanzania

Luk, A. L., \& Shek, D. T. L. (2006). "Changes in Chinese discharged chronic mental patients attending a psychiatric rehabilitation program with holistic care elements: A quasiexperimental study," TSW Holistic Health and Medicine, 1, 71-83.

Luk, A. L., Chan, B.P.S., Cheong, S. W., \& Ko, S. K. K. (2010). "An exploration of the burnout situation on teachers in two schools in Macau," Social Indicators Research, 95, 489502.

Melo, P. (2003). "Ethical conflicts in teaching: The novice teacher's experience," Connections, 175-189.

Orodho, J. A. (2009). Elements of education and social science research methods (2 ${ }^{\text {nd }}$ ed.). Maseno-Kenya: Kanezja Publisher.

Pehlivan, I. (1998). Management of professional and organizational ethics. Ankara: Pegem Publishing.

Sumra, S. (2004). The living and working conditions of teachers in Tanzania: A research report. Dar es salaam: HakiElimu. Retrieved on $27^{\text {th }}$ June 2011 from http://old.eiie.org/healthandsafety/file/\%282005\%29\%20Living\%20and\%20Working\%20Conditio ns\%20of\%20Teachers\%20in\%20Tanzania\%20en.pdf.

Van Nuland, S., \& Khandelwal, B. P. (2006). Ethics in education: The role of teacher codes Canada and South Asia. Paris: UNESCO.

Zhao, Y., \& Bi, C. (2003). Job burnout and the factors related to it among middle school teachers. Psychological Development and Education, 1, 80-84. 